\title{
Studies on the Expired Alveolar Carbon Dioxide Tension in Chronic Pulmonary Emphysema with Special Reference to Pulmonary Arterial Hypertension
}

\author{
Atsushi SAKAMOTO, M.D. and Makoto MURAO, M.D.*
}

A total number of 68 cases were examined in the present study. Continuous analysis of expired alveolar $\mathrm{CO}_{2}$ tension, using a rapid infrared meter, was made in 10 normal subjects and 20 patients with chronic pulmonary diseases. In 17 patients, an arterial blood was sampled simultaneously, while alveolar $\mathrm{CO}_{2}$ tension was analyzed during quiet breathing. This allowed to make a direct comparison between blood and gas tensions. Cardiac catheterization was carried out in 38 patients with emphysema, and the mixed venous $\mathrm{CO}_{2}$ tension and mean pulmonary artery pressure were measured. The mean pulmonary artery pressure exceeded $18 \mathrm{~mm} . \mathrm{Hg}$ in 23 of 38 patients, and in all patients with a mixed venous $\mathrm{CO}_{2}$ tension of more than $55 \mathrm{~mm}$. $\mathrm{Hg}$. The mixed venous $\mathrm{CO}_{2}$ tension exceeded $50 \mathrm{~mm}$. Hg in 23 of 38 patients, and the correlation between mixed venous $\mathrm{CO}_{2}$ tension and pulmonary artery pressure was highly significant in these 23 patients $(R=+0.84)$. These results indicate that the severity of pulmonary hypertension may be estimated by the expired alveolar $\mathrm{CO}_{2}$ tension in patients with a mixed venous $\mathrm{CO}_{2}$ tension of more than $55 \mathrm{~mm}$. $\mathrm{Hg}$.

$\mathrm{W}$

ITH the recent availability of rapid $\mathrm{CO}_{2}$ analyzers, DuBois and Fowler have explored a new field in continuous analysis of expired $\mathrm{CO}_{2}$ tension for estimation of various values pertaining to mixed venous $\mathrm{CO}_{2}$ tension, arterial $\mathrm{CO}_{2}$ tension, uneven ventilation-perfusion relationship, ratio of pulmonary blood flow per equivalent lung volume, and also cardiac output. ${ }^{1)-5}$ ( These values are really essential in evaluating the respiratory insufficiency and pulmonary circulatory disturbance in patients with chronic pulmonary diseases, ${ }^{6)}$ and it seems very convenient for the clinical application that the values are obtained without hazardous procedures such as arterial puncture or cardiac catheterization. In this paper, an attempt has been made on normal subjects and patients with chronic pulmonary emphysema to reevaluate the continuous analysis of expired $\mathrm{CO}_{2}$ tension following the method of Silvertson and Fowler, and clinical applicability of the methods is also discussed.

\section{Materials and Methods}

Ten normal individuals were studied for the control, of whom 8 were men and 2

From the Second Department of Internal Medicine, Faculty of Medicine, University of Tokyo, Tokyo.

* Associate Professor of Internal Medicine. 
were women, ranging in age from 19 to 38 years. Twenty patients with chronic pulmonary diseases were also studied, 10 of whom had pulmonary emphysema, ranging in age from 41 to 67 years, with an average of 55 years. The other 10 cases of chronic pulmonary diseases included 4 cases of bronchial asthma, 2 cases of pulmonary fibrosis, 2 cases of chronic bronchitis, and one case each of beryllium poisoning and bronchiectasis.

The method used in this tudy was smilar to that originally described by Sivertson and Fowler. ${ }^{4}$ The infrared $\mathrm{CO}_{2}$ meter* and its standard cell, through which the subject breathed, was set up as such that the distal end of the sampling tube of the $\mathrm{CO}_{2}$ meter was connected to a prime mover of pneumotachograph. The prime mover was a Lilly type, which had an internal volume of $70 \mathrm{ml}$., and a flow resistance of $1.15 \mathrm{~cm} . \mathrm{H}_{2} \mathrm{O}$ per liter per second. The total volume of dead space was no more than $150 \mathrm{ml}$. The pick-up system of the prime mover was a type of wire resistance strain gauge differential manometer. ${ }^{*}$ A warm-up period of 2 hours or more provided sufficient stability for sensitivity of the instruments. Then the infrared $\mathrm{CO}_{2}$ analyzer was calibrated with mixtures of $\mathrm{CO}_{2}$ in room air, which had been previously analyzed with a Scholander's apparatus. Dry gas concentrations were changed to tension by multiplying with the barometric pressure corrected for water vapor tension at body temperature. Calibrations were made before and after each test, and over-all accuracy of $\mathrm{CO}_{2}$ tension described below was considered to be $\pm 1 \mathrm{~mm}$. Hg. The $\mathrm{CO}_{2}$ detector system was capable of $100 \%$ response in a 0.05 second and 0.2 second, when the rate of air flow was $500 \mathrm{ml}$. per second and $100 \mathrm{ml}$. per second respectively. Both $\mathrm{CO}_{2}$ tension and ventilatory volume were recorded with an ink-writing oscillograph*** at a paper speed of 6 or $10 \mathrm{~mm}$. per second. The area of the flow tracing, as it was deflected from zero line by each breath, was converted into a volume by planimetry or by counting squares. All volumes were corrected to BTPS.

Wearing a nose clip, subjects sat in chairs during a suitable rest period. Then they breathed room air through a mouth-piece attached to the sampling tube. $\mathrm{CO}_{2}$ and tidal volumes were recorded for several natural breaths and for a forced maximal expiration following normal inspiration (Fig. 1). Recordings were made for a maximal expiration following breathholding at the inspiratory level of the normal ending (Fig. 2). The period of breathholding was intended to be 25 seconds or longer, as could be tolerated. All the procedure mentioned above was repeated and recorded. Then recordings were also made before and during 30 seconds of voluntary hyperventilation terminated by a forced maximal expiration (Fig. 3). For hyperventilation, subjects were directed to take approximately 12 breaths in 30 seconds.

Thirty-eight patients with chronic pulmonary emphysema were studied by right heart catheterization, and the partial pressure of $\mathrm{CO}_{2}$ in the mixed venous blood and the mean pulmonary artery pressure were measured. ${ }^{7)}$ In 17 patients, an indwelling needle was inserted into the brachial artery and arterial blood was sampled, while the expired alveolar gas was analyzed continuously during natural breathing. The whole blood was analyzed for $\mathrm{CO}_{2}$ and $\mathrm{O}_{2}$ by the method of Van Slyke and Neill.

* Liston-Becker Model 16 Beckman Co.

** Toyosokki Co. DLPU-0.03.

*** Nihonkoden Co. W 1-40. 
Subject M.M. Normal

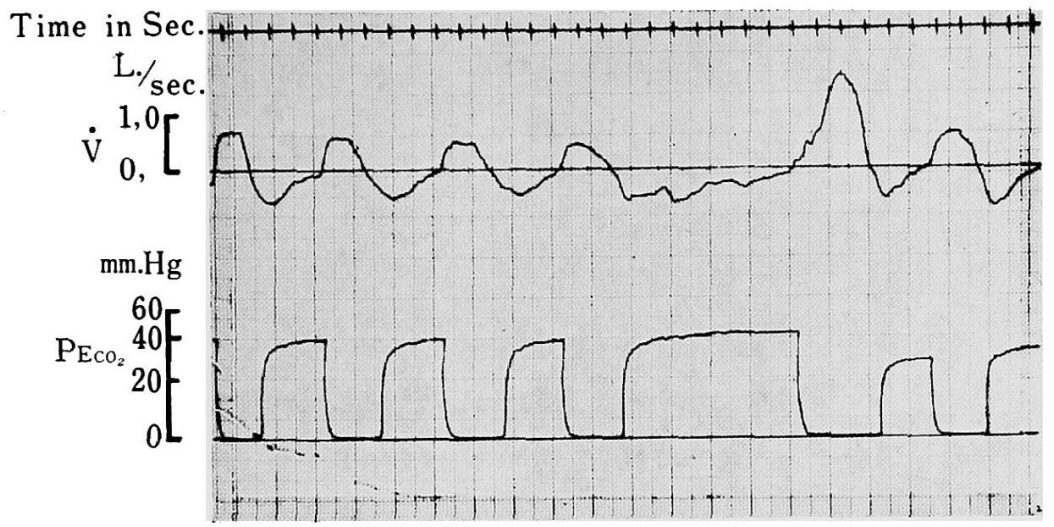

Fig. 1. Record of expired $\mathrm{CO}_{2}$ tension analysis during normal respiration and forced expiration.

Subject M.M. Normal



Fig. 2. Estimation of $\mathrm{P}_{\overline{\mathrm{V}} \mathrm{CO}_{2}}$ by the $\mathrm{CO}_{2}$ tension curve during forced expiration after breathholding (19 sec.).

The $\mathrm{pH}$ was determined with Cambridge $\mathrm{pH}$ meter* and the packed cell volume by the method of Wintrobe. The $\mathrm{CO}_{2}$ tension of blood was determined from the nomogram of Singer and Hastings. ${ }^{8)}$

\section{RESULTS}

Data of routine pulmonary function tests and that of $\mathrm{CO}_{2}$ tension which represent the maximal value for any single expiration are summarized in Table I.

\section{Results in Normal Subjects-}

The largest variations in end-tidal $\mathrm{CO}_{2}$ tension during a 45 second-

\footnotetext{
* 4427 Cambridge pH meter, portable pattern.
} 


\section{Subject A.N. Emphysema}

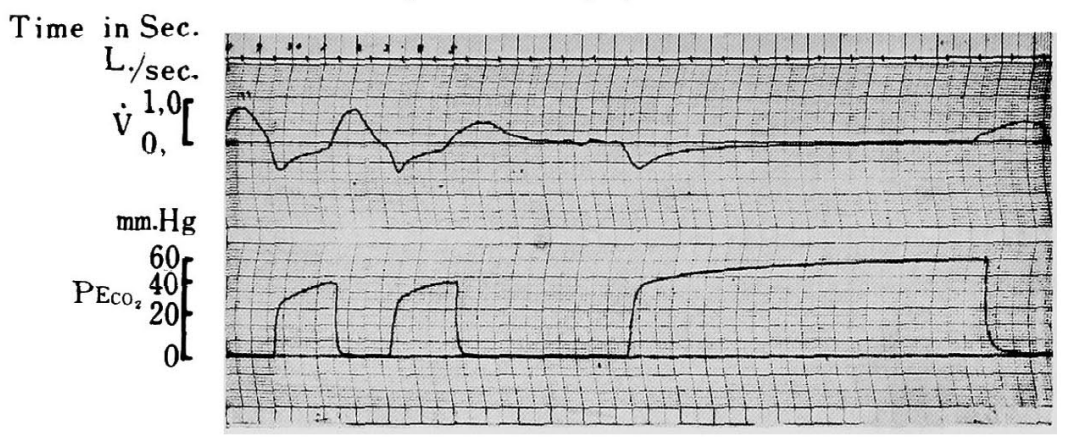

Fig. 3. Record of expired $\mathrm{CO}_{2}$ tension analysis during hyperventilation and terminal forced expiration.

period in 10 normal subjects were ranging from 1.0-3.0 mm.Hg. During quiet breathing prior to a forced expiration, there was a plateau observed at each end-expiration (Fig. 1). The mean of average end-tidal values for each subject was $38.5 \mathrm{~mm} . \mathrm{Hg}$. At the end of normal inspiration following quiet breathing, the breathing was held for an average of 23 seconds. In this case, the alveolar plateau by succecding forced cxpiration was essentially horizontal during an expiration of a liter or more for several seconds (Fig. 2). As mixed venous $\mathrm{CO}_{2}$ tension has been essentially unchanged for 23 seconds or more in these cases, the maximal values of $\mathrm{CO}_{2}$ tension of maximal expiration after the breathholding were considered to represent the mixed venous $\mathrm{CO}_{2}$ tension (oxygenated). ${ }^{4}$ ) The average value of estimated mixed venous $\mathrm{CO}_{2}$ tensions was $45.7 \mathrm{~mm} . \mathrm{Hg}$ in normal subjects. With maximal expiration following natural breathing, there always occurred slight increase in $\mathrm{CO}_{2}$ tension (Fig. 1), reaching an average value of $41.8 \mathrm{~mm} . \mathrm{Hg}$, at the average value of 2,050 ml. of expired volume (Table I). Assuming that the observed rate of increase in expired alveolar $\mathrm{CO}_{2}$ tension is equal to that of alveolar $\mathrm{CO}_{2}$ tension, after about $500 \mathrm{ml}$. of gas was expired and anatomic dead space was washed out, Fick's principle may be applied to the observed rate of increase in expired alveolar $\mathrm{CO}_{2}$ tension as a function of time. This expression was shown in the papers of DuBois and Fowler as follows ${ }^{4) 9)}$ :

$$
\frac{\Delta \mathrm{P}_{\mathrm{ACO}_{2}}}{\Delta \mathrm{t}}=\frac{\left(\mathrm{P}_{\mathrm{V}^{-} \mathrm{O}_{2}}-\mathrm{P}_{\mathrm{ACO}_{2}}\right)(\text { diss. slop }) \dot{\mathrm{Q}}\left(\mathrm{P}_{\mathrm{B}}-47\right)}{\mathrm{ELV}}
$$

$\mathrm{P}_{\mathrm{ACO}_{2}}$ : partial pressure of $\mathrm{CO}_{2}$ in the alveolar gas at given time.

$\mathrm{P}_{\mathrm{vCO}_{2}}$ : partial pressure of $\mathrm{CO}_{2}$ in the mixed venous blood, oxygenated. diss. slope: the mean slope of the dissociation curve for $\mathrm{CO}_{2}$ and oxygenated whole blood, normally about 0.46 volume per cent per $\mathrm{mm} . \mathrm{Hg}$.

$\dot{\mathrm{Q}}$ : rate of alveolar blood flow.

$\mathrm{P}_{\mathrm{B}}$ : barometric pressure, expressed in mm.Hg $(760 \pm 8 \mathrm{~mm} . \mathrm{Hg}$ in Tokyo, Japan). 
Table I. Characteristics of Several Types of Breathing

\begin{tabular}{|c|c|c|c|c|c|c|c|c|c|}
\hline & \multirow{2}{*}{\multicolumn{3}{|c|}{ Normal }} & \multicolumn{6}{|c|}{ Chronic pulmonary diseases } \\
\hline & & & & \multicolumn{3}{|c|}{ Emphysema } & \multicolumn{3}{|c|}{ Miscellaneous } \\
\hline & No. & Mean & Range & No. & Mean & Range & No. & Mean & Range \\
\hline Rest & 10 & & & 10 & & & 10 & & \\
\hline $\mathrm{V}_{\mathrm{T}}(\mathrm{ml})$ & & 570 & $380 \sim 850$ & & 500 & $300 \sim 750$ & & 580 & $330 \sim 790$ \\
\hline$V^{1}($ L. $/$ min. $)$ & & 9.0 & $5.3 \sim 13.5$ & & 9.0 & $5.9 \sim 15.0$ & & 10.2 & $8.4 \sim 13.3$ \\
\hline f (resp./min.) & & 16 & $9 \sim 19$ & & 18 & $13 \sim 22$ & & 18 & $11 \sim 30$ \\
\hline $\mathrm{Max} . \mathrm{PCO}_{2}(\mathrm{~mm} . \mathrm{Hg})$ & & 38.5 & $35 \sim 44$ & & 39.0 & $31 \sim 48$ & & 35.9 & $29 \sim 43$ \\
\hline $\begin{array}{l}\text { Vol. (ml.) } \\
\text { Vox }\end{array}$ & & 2,050 & $1,060 \sim 2,870$ & & 1,340 & $740 \sim 2,480$ & & 1,890 & $1,320 \sim 2,410$ \\
\hline Dur. (sec.) & & 7.7 & $3.4 \sim 11.5$ & & 9.9 & $5.5 \sim 17.6$ & & 9.3 & $3.2-13.8$ \\
\hline $\mathrm{Max} . \mathrm{Pco}_{2}(\mathrm{~mm} \cdot \mathrm{Hg})$ & & 41.8 & $36 \sim 46$ & & 52,9 & $45 \sim 67$ & & 44.2 & $35 \sim 50$ \\
\hline Hyperventilation & 10 & & & 10 & & & 10 & & \\
\hline $\begin{array}{c}\mathrm{PCO}_{2} \text { before } \mathrm{HV} \\
(\mathrm{mm} . \mathrm{Hg})\end{array}$ & & 37.1 & $31 \sim 43$ & & 38.5 & $33 \sim 44$ & & 34.4 & $30 \sim 40$ \\
\hline Dur. (sec.) & & 29 & $27 \sim 32$ & & 30 & $25 \sim 37$ & & 31 & $28 \sim 35$ \\
\hline$V_{T}(\mathrm{ml})$. & & 1,840 & $1,150 \sim 3,120$ & & 780 & $460 \sim 1,690$ & & 1,580 & $840 \sim 3,220$ \\
\hline$V^{\prime}($ L. $/$ min. $)$ & & 43 & $23 \sim 77$ & & 18 & $10 \sim 47$ & & 31 & $16 \sim 55$ \\
\hline $\begin{array}{l}f(\text { resp./min. }) \\
\mathrm{Max} . \mathrm{PCO}_{2} \text { (lowest }\end{array}$ & & 23 & $18 \sim 33$ & & 23 & $13 \sim 36$ & & 21 & $13 \sim 40$ \\
\hline $\begin{array}{l}3 \text { end-tidal) } \\
\text { aax. expiration } \\
\text { after HV }\end{array}$ & & 20.8 & $17 \sim 26$ & & 31.9 & $24 \sim 38$ & & 24.6 & $20 \sim 28$ \\
\hline Vol. (ml.) & & 3,210 & $2,000 \sim 5,230$ & & 1,600 & $820 \sim 3,380$ & & 2,340 & $1,470 \sim 3,140$ \\
\hline Dur. (sec.) & & 4.9 & $2.6 \sim 7.8$ & & 10.0 & $3.4 \sim 11.3$ & & 8.7 & $4.7-16.9$ \\
\hline Max. $\mathrm{Pco}_{2}(\mathrm{~mm} \cdot \mathrm{Hg})$ & & 26.3 & $20 \sim 35$ & & 46.5 & $37 \sim 58$ & & 33.2 & $25 \sim 43$ \\
\hline $\begin{array}{l}\text { Breathholding } \\
\text { Dur. BH. (sec.) } \\
\text { Max. exp. after BH }\end{array}$ & 10 & 23 & $17 \sim 36$ & $\begin{array}{r}10 \\
9\end{array}$ & 19 & $12 \sim 27$ & 10 & 22 & $14 \sim 27$ \\
\hline Vol. (ml.) & & 1,880 & $1,220 \sim 2,520$ & 10 & 1,270 & $690 \sim 1,950$ & & 1,740 & $1,120 \sim 2,400$ \\
\hline Dur. (sec.) & & 6.1 & $2.7 \sim 12.0$ & & 7.8 & $3.3 \sim 17.5$ & & 6.4 & $3.9 \sim 16.0$ \\
\hline Max. $\mathrm{Pco}_{2}(\mathrm{~mm} . \mathrm{Hg})$. & & 45.7 & $41 \sim 51$ & & 55.6 & $48 \sim 66$ & & 48.1 & $40 \sim 52$ \\
\hline $\begin{array}{l}\text { RV/TLC }(\%) \\
\text { MBC (L./min.) } \\
\text { MBC (\% of pre- }\end{array}$ & 8 & $\begin{array}{r}23 \\
126\end{array}$ & $\begin{array}{l}19 \sim 28 \\
89 \sim 166\end{array}$ & $\begin{array}{r}10 \\
9\end{array}$ & $\begin{array}{l}61 \\
33\end{array}$ & $\begin{array}{ll}52 \sim & 68 \\
16 \sim 79\end{array}$ & 9 & $\begin{array}{l}38 \\
56\end{array}$ & $\begin{array}{l}24 \sim \quad 48 \\
27 \sim 107\end{array}$ \\
\hline $\begin{array}{l}\text { dicted) } \\
\mathrm{MMF}(\mathrm{L} . / \mathrm{sec} .) \\
\mathrm{SaO}_{2}(\%) \\
\mathrm{pHa} \\
\mathrm{PaCO}_{2}(\mathrm{~mm} \cdot \mathrm{Hg})\end{array}$ & & 4.1 & $2.6 \sim 5.9$ & 8 & $\begin{array}{r}43 \\
0.50 \\
91 \\
7.38 \\
49.3\end{array}$ & $\begin{array}{r}26 \sim 92 \\
0.18 \sim 1.22 \\
75 \sim 98 \\
7.33 \sim 7.46 \\
39 \sim 62\end{array}$ & & $\begin{array}{r}57 \\
1.37 \\
96 \\
7.42 \\
39.3\end{array}$ & $\begin{array}{r}33 \sim 95 \\
0.28 \sim 4.2 \\
93 \sim 100 \\
7.38 \sim 7.46 \\
35 \sim 44\end{array}$ \\
\hline
\end{tabular}

Note: $\mathrm{CO}_{2}$ tensions are maximal values of any single expiration.

$\begin{array}{lll}\mathrm{V}_{\mathrm{T}}: \text { Tidal volume } & \mathrm{MBC}: \text { Maximal breathing capacity } \\ \mathrm{V} & \mathrm{MMF}: \text { Maximal midexpiratory flow } \\ \mathrm{f} & : \text { Respiratory frequency } & \mathrm{SaO}_{2}: \text { Arterial blood oxygen saturation } \\ \mathrm{RV}: \text { Residual volume } & \mathrm{pHa}: \text { Arterial blood } \mathrm{pH} \\ \mathrm{TLC}: \text { Total lung capacity } & \mathrm{Paco}_{2}: \text { Arterial carbon dioxide tension }\end{array}$

ELV: 'Equivalent lung volume for $\mathrm{CO}_{2}$ at a given time' includes the capacity of the alveolar gas, pulmonary capillary blood and tissue for $\mathrm{CO}_{2}$.

The integrated form of the equation (1) is:

$\mathrm{P}_{\mathrm{ACO}_{2}}=\mathrm{P}_{\overline{\mathrm{V}} \mathrm{CO}_{2}}-\left(\mathrm{P}_{\overline{\mathrm{V}} \mathrm{CO}_{2}}-\mathrm{P}_{\mathrm{AoCO}_{2}}\right) \mathrm{e}^{-\mathrm{kt}}$

$\mathrm{P}_{\mathrm{AoCO}_{2}}$ : the value of $\mathrm{P}_{\mathrm{ACO}_{2}}$ at zero time.

$$
\mathrm{k}=\frac{\text { (diss. slope) } \dot{\mathrm{Q}}\left(\mathrm{P}_{\mathrm{B}}-47\right)}{\mathrm{ELV}}
$$


The difference between the mixed venous tension and the successive alveolar tension was measured on several points of each record of maximal expirations and the logarithm of the difference was plotted against the time from the onset of expiration, as illustrated in Fig. 4. As seen in Fig. 5,



Fig. 4. Mixed venous-alveolar $\mathrm{CO}_{2}$ tension gradient during forced expiration on the record shown in Fig. 1. The arrows show the points of the initial alveolar $\mathrm{CO}_{2}$ tension of 2 nd and 3rd phase. Estimation of $\mathrm{P}_{\overline{\mathrm{V}} \mathrm{CO}}$ is based on the breathholding method shown in Fig. 2.

we divided each record of forced expirations into three phases. After an average value of $480 \mathrm{ml}$. had been expired (designated as ' 1 st phase'), the rate of decrease (per cent per second) in the tension difference, $\mathrm{P}_{\overline{\mathrm{V}} \mathrm{CO}_{2}}-\mathrm{P}_{\mathrm{ACO}}$, became constant for the period during which an average of 1,030 ml. was expired (designated as ' 2 nd phase'). In Fig. 6, the mean rate of increase in expired alveolar $\mathrm{CO}_{2}$ tension in the 2 nd phase $\left(\Delta \mathrm{P}_{\mathrm{ACO}_{2}} / \Delta \mathrm{t}\right)$ was plotted against each initial gradient, which represented the difference at the initial $\mathrm{P}_{\mathrm{ACO} 2}$ in the 2nd phase $\left(\mathrm{P}_{\overline{\mathrm{V}} \mathrm{CO}_{2}}\right.$-initial $\left.\mathrm{P}_{\mathrm{ACO}_{2}}\right)$. In this Fig. 6 , the percentage rate of change in the initial gradient was represented by the angle of the straight line connected with the zero point. The average value of $\dot{Q} / E L V$ was calculated from the mean percentage rate of decrease for each group by substitution in the equation (1), and these values were shown in Table II. In normal subjects, the mean rate of increase in $\mathrm{P}_{\mathrm{ACO}_{2}}$ in the 2nd phase had an average value of $11 \mathrm{~mm} . \mathrm{Hg}$ and decreased about 21 per cent per second. It was corresponding to an average value of 3.8 liters blood flow per minute per liter of lung volume (Tablc II). The upward slope of the alvolar plateau decreased progressively toward the end of forced expirations. In the 3rd phase, the 
Subject. M.M. Normal.

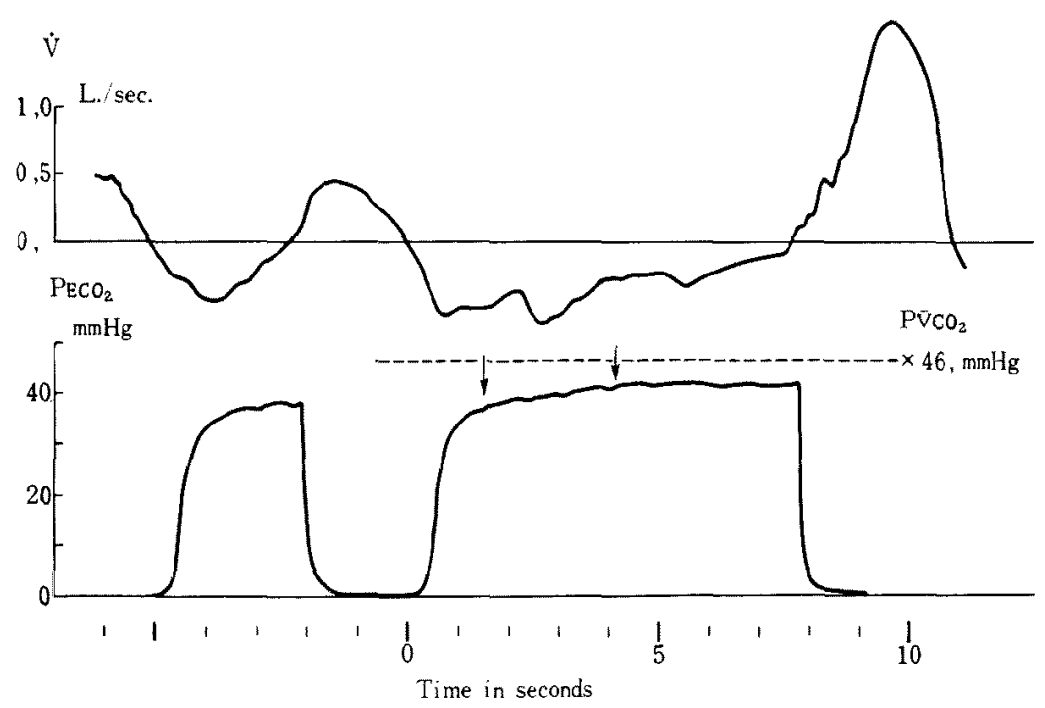

Fig. 5. $\mathrm{CO}_{2}$ tension curve during normal and forced expiration on the record shown in Fig. 1. The arrows show the same points indicating the initial alveolar $\mathrm{CO}_{2}$ tension in Fig. 4.



Fig. 6. Correlation between mean rate of increase in alveolar $\mathrm{CO}_{2}$ tension and mixed venous-initial alveolar $\mathrm{CO}_{2}$ tension gradient in the 2 nd phase. 
plateau was almost horizontal, although it showed small variations (Fig. 5). As noted by the more horizontal course of the last three points of Fig. 4, semilogarithmic plots of $\mathrm{P}_{\overline{\mathrm{V}} \mathrm{CO}_{2}}-\mathrm{P}_{\mathrm{ACO}}$ showed that the percentage rate of decrease became less in the 3 rd phase. Similar analyses were made for maximal expirations following hyperventilation (Fig. 7).

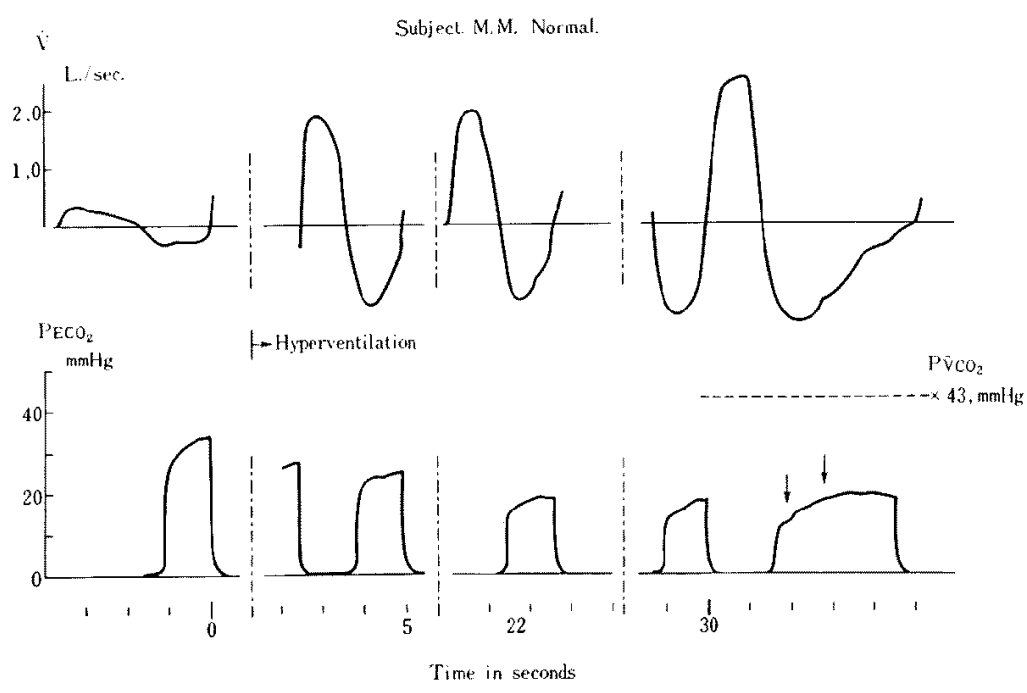

Fig. 7. $\mathrm{CO}_{2}$ tension during hyperventilation and terminal forced expiration.

The arrows show the points indicating the initial alveolar $\mathrm{CO}_{2}$ tension.

With voluntary hyperventilation, 10 normal subjects increased their minute volume to an average value of 43 liters per minute, as such of 4.8 times at rest. During hyperventilation, end-tidal values of $\mathbf{P}_{\mathrm{ACO}_{2}}$ decreased for the first several breaths and then decreased little as long as the respiratory rate was similar. The mean value for the average $\mathrm{P}_{\mathrm{ACO}_{2}}$ of the lowest three expirations for each subject was $20.8 \mathrm{~mm} . \mathrm{Hg}$, as presented in Table I. On the succeeding forced expiration, maximal $\mathrm{CO}_{2}$ tension had an average value of $26.3 \mathrm{~mm} . \mathrm{Hg}$, at average expired volume of $3,210 \mathrm{ml}$. during the period of 4.9 seconds. In some records of some cases, maximal values of expired $\mathrm{CO}_{2}$ tension were observed prior to the end of expiration (Fig. 7). The semilogarithmic plots of $\mathrm{P}_{\mathrm{V}_{\mathrm{CO}}}-\mathrm{P}_{\mathrm{ACO}_{2}}$ showed a period of constant percentage rate of decrease, during which an average 2,100 $\mathrm{ml}$. of gas was expired (2nd phase). With hyperventilation, the values of the initial gradient and mean rate of change in $\mathrm{P}_{\mathrm{ACO}_{2}}$ increased in the 2 nd phase, but the percentage rate of change was about-18 per cent per second (Table II). Average values of durations were shortened in three phases.

Results in Chronic Pulmonary Diseases-

After comprehensive case history and pulmonary function tests including 


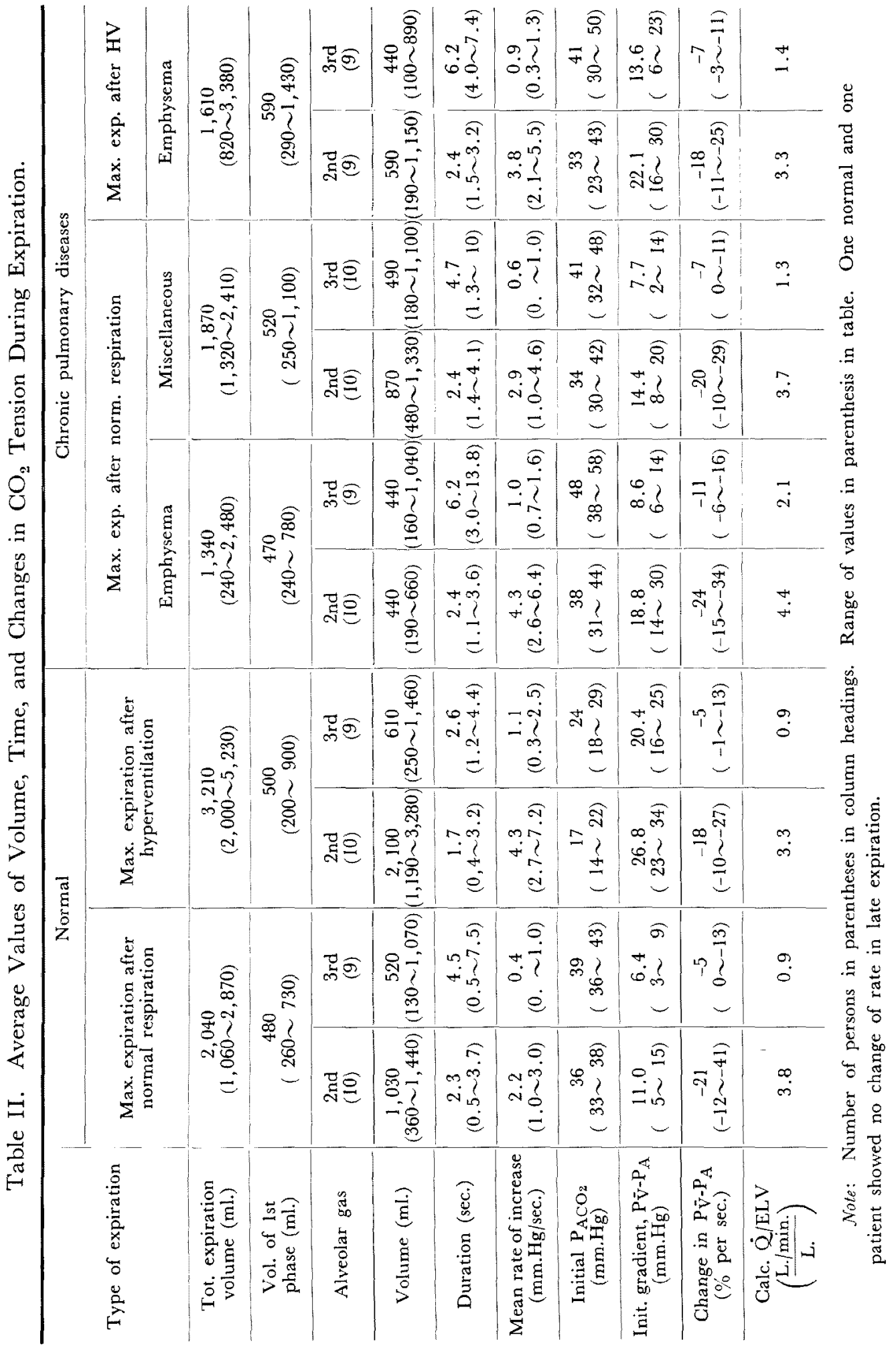


fluoroscopic examination, 20 patients were divided into 2 groups which consisted of 10 typical pulmonary emphysema and 10 cases with other forms of pulmonary disease. Data listed in Table I indicate that pulmonary insufficiency is compensated better by hyperventilation in the miscellaneous group than in the emphysema group at rest. In these patients, the breath-tobreath variation in resting end-tidal $\mathrm{P}_{\mathrm{ACO} 2}$ was greater than that of normal subjects, ranging from 1.3-4.8 mm.Hg during a 45-second period. In many cases of pulmonary disease, resting end-tidal $\mathrm{P}_{\mathrm{ACO}_{2}}$ was frequently less than normal. However, with a forced expiration, an increase in $\mathrm{P}_{\mathrm{ACO} 2}$ of about $10 \mathrm{~mm} . \mathrm{Hg}$ was observed, reaching average values of 52.9 and 44.2 $\mathrm{mm} . \mathrm{Hg}$ in emphysema group and others respectively. In patients with emphysema listed in Table I, maximal expirations following natural breathing were prolonged (an average value of 9.9 seconds of duration) and the expired volumes were smaller (an average value of 1,340 ml.) than normal. Nine of 10 patients with emphysema held their breath for 12 to 27 seconds, averaging 19 seconds. The alveolar plateau of maximal expirations after breathholding was essentially horizontal during an expiration of the last 0.8 liter during several seconds (Fig. 8). In these patients, as well as in normal sub-

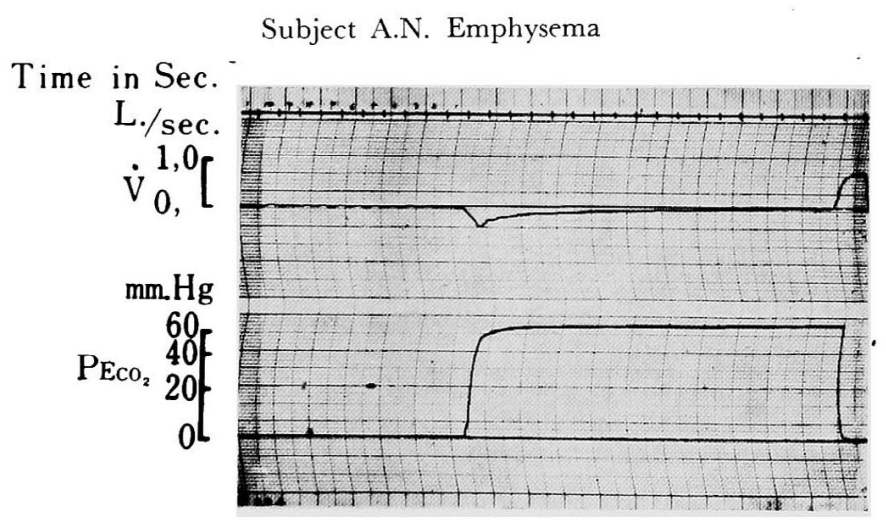

Fig. 8. Estimation of $\mathrm{P}_{\overline{\mathrm{V}} \mathrm{CO}_{2}}$ by the $\mathrm{CO}_{2}$ tension curve during forced expiration after breathholding (21 sec.).

jects, the maximal values of these alveolar plateau tensions appeared to represent $\mathrm{P}_{\overline{\mathrm{V}} \mathrm{CO}_{2}}$, averaging $55.6 \mathrm{~mm} . \mathrm{Hg}$ (Table $\mathrm{I}$ ). The semilogarithmic plots were made for maximal expirations and they also showed a constant percentage rate of decrease in the 2nd phase, during which an average $440 \mathrm{ml}$. of gas was expired (Fig. 9). In cases of emphysema, the mean rate of increase in $\mathrm{P}_{\mathrm{ACO}_{2}}$ in 2nd phase had an average value of $4.3 \mathrm{~mm} . \mathrm{Hg}$ per second, which was equal to that observed in normal subjects in the 2nd phase of maximal expiration following hyperventilation. The relatively large average value of 18 $\mathrm{mm} . \mathrm{Hg}$ of initial gradient was observed, and it decreased at the rate of about 24 per cent per second. In the $3 \mathrm{rd}$ phase, the mean rate of increase in $\mathbf{P}_{\mathrm{AcO}_{2}}$ had an average value of $1.0 \mathrm{~mm} . \mathrm{Hg}$ per second, which was similar to that 


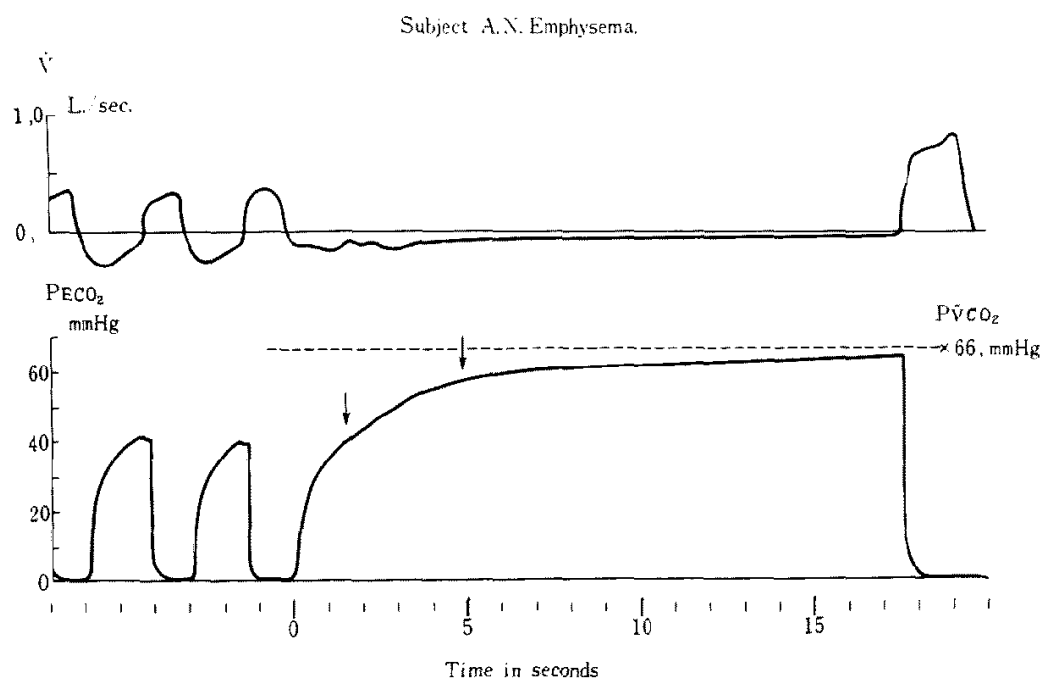

Fig. 9. $\mathrm{CO}_{2}$ tension curve during nomal and forced expiration. Estimation of $\mathrm{P} \overline{\mathrm{V}}_{\mathrm{CO}}$ is based on the breathholding method shown in Fig. 8 . Arrows show the points of the initial alveolar $\mathrm{CO}_{2}$ tension.

value observed in normal subjects in the same 3rd phase of the maximal expiration following hyperventilation (Table II).

The patients with emphysema showed less response to voluntary hyperventilation than normal subjects and their average minute value was 18 liters per minute. As the reductions of end-tidal values did not exceed several mm.Hg during hyperventilation, it appeared that an effective alveolar ventilation of emphysematous lungs could not be increased voluntarily. With the succeeding forced expiration, the increase in the expired volumes was smaller in patients with emphysema than in normal subjects. The maximal $\mathrm{P}_{\mathrm{ACO}}$ of the succeeding forced expiration, with a mean of $46.5 \mathrm{~mm} . \mathrm{Hg}$, exceeded the resting end-tidal value in all cases. These expirations were plotted semilogarithmically and divided into three phases (Fig. 10). In many cases of emphysema, the maximal value of expiratory flow rate of each forced expiration was observed within the 1st phase (Fig. 11). In the 2nd phase of maximal expiration following hyperventilation, an average value of $590 \mathrm{ml}$. for the expired volume was obtained, and the increase in expired volumes was far less than normal. An average duration remained unchanged throughout three phases, after hyperventilation. The mean rate of increase in $\mathrm{P}_{\mathrm{ACO}}$ in the 2 nd phase had an average value of $3.8 \mathrm{~mm}$. Hg per second, which was similar to those observed during a forced expiration after natural breathing. The initial gradient was slightly increased, averaging $22.1 \mathrm{~mm} . \mathrm{Hg}$. This resulted in the value of about -18 per cent per second for the calculated percentage rate of decrease (Table II). Ten patients with miscellaneous pulmonary diseases showed intermediate values of the gradient and its rate of change.

Increase in alveolar $\mathrm{CO}_{2}$ tension $\left(\Delta \mathrm{P}_{\mathrm{ACO}_{2}}\right)$ and volume of expired alveolar 


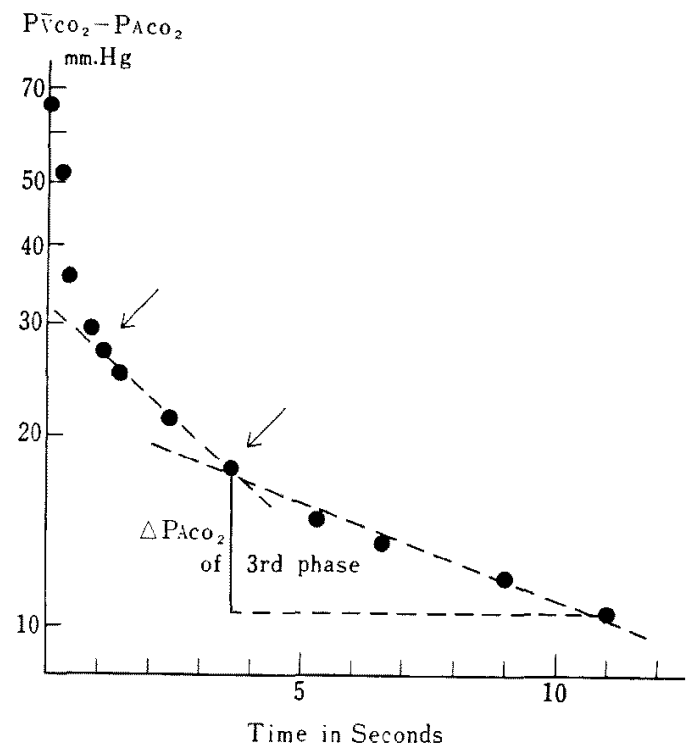

Fig. 10. Mixed venous-alveolar $\mathrm{CO}_{2}$ tension gradient during forced expiration on the record shown in Fig. 3. Estimation of $\mathrm{P}_{\overline{\mathrm{V}} \mathrm{CO}_{2}}$ is based on the breathholding method shown in Fig. 8. Arrows show the points of the initial alveolar $\mathrm{CO}_{2}$ tension of $2 \mathrm{nd}$ and $3 \mathrm{rd}$ phase.



Fig. 11. $\mathrm{CO}_{2}$ tension curve during hyperventilation and terminal forced expiration on the record shown in Fig. 3. The arrows show the same points indicating the initial alveolar $\mathrm{CO}_{2}$ tension in Fig. 10.

gas in the 2nd phase of maximal expiration were plotted in Fig. 12. In patients with emphysema, the differences from normal findings were larger $\Delta \mathrm{P}_{\mathrm{ACO} 2}$ and smaller volumes of expired alveolar gas. These 2 components 


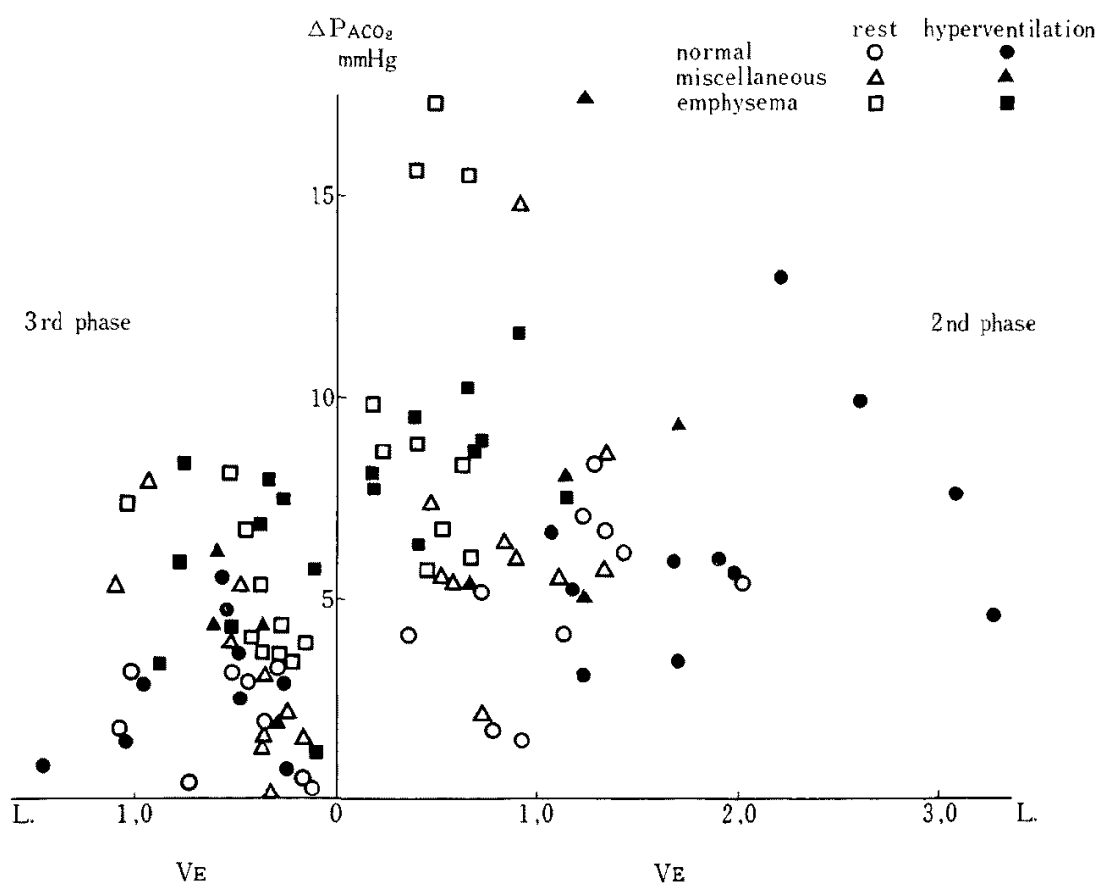

Fig. 12. Increase in alveolar $\mathrm{CO}_{2}$ tension plotted against volume of expired alveolar gas (2nd and $3 \mathrm{rd}$ phase).

were divided by a duration of the 2 nd phase for each subject, and a correlation between the mean rate of increase in alveolar $\mathrm{CO}_{2}$ tension $\left(\Delta \mathrm{P}_{\mathrm{ACO}_{2}} / \Delta \mathrm{t}\right)$ and mean rate of air flow in the 2 nd phase was obtained (Fig. 13). As shown in Fig. 13, $\Delta \mathrm{P}_{\mathrm{ACO}_{2} / \Delta t}$ and the mean rate of air flow increased in normal subjects after hyperventilation, but did not increase in patients with emphysema. As plotted in Fig. 14, a significant correlation between $\mathrm{P}_{\mathrm{V}_{\mathrm{CO}}}$ and mean pulmonary artery pressure was observed in 38 patients with emphysema $(\mathrm{R}=+0.67)$. The mean pulmonary artery pressure exceeded $18 \mathrm{~mm} . \mathrm{Hg}$ in 23 of 38 patients, and in all patients with a $\mathrm{P}_{\overline{\mathrm{VCO}}}^{-}$of more than $55 \mathrm{~mm} . \mathrm{Hg}$. The $\mathrm{P}_{\overline{\mathrm{v}} \mathrm{CO}_{2}}$ exceeded $50 \mathrm{~mm} . \mathrm{Hg}$ in 23 of 38 patients, and the correlation between $\mathrm{P}_{\overline{\mathrm{V}}} \mathrm{PO}_{2}$ and pulmonary artery pressure was highly significant in these 23 patients $(\mathrm{R}=+0.84)$.

\section{Discussion}

In general, the difficulty of forced expiration in patients with emphysema is due to the check valve mechanism. ${ }^{10}$ ) This is well demonstrated by the fact that a forced expiration shows a peaking of expiratory flow early in expiration, followed by a rapid decrease to the lower rate of flow, namely the "leakage flow'. By a forced maximal expiration after deep inspiration, these characteristics of the pattern of expiratory flow were distinguished in patients with emphyscma (Fig. 11). In normal subjects it has been known that the rate of 


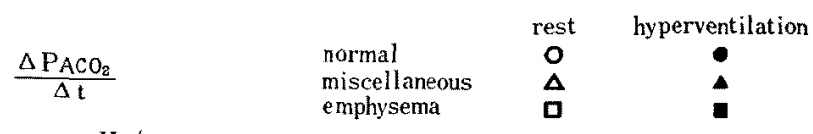

$\mathrm{mmHg} / \mathrm{sec}$.

emphysema

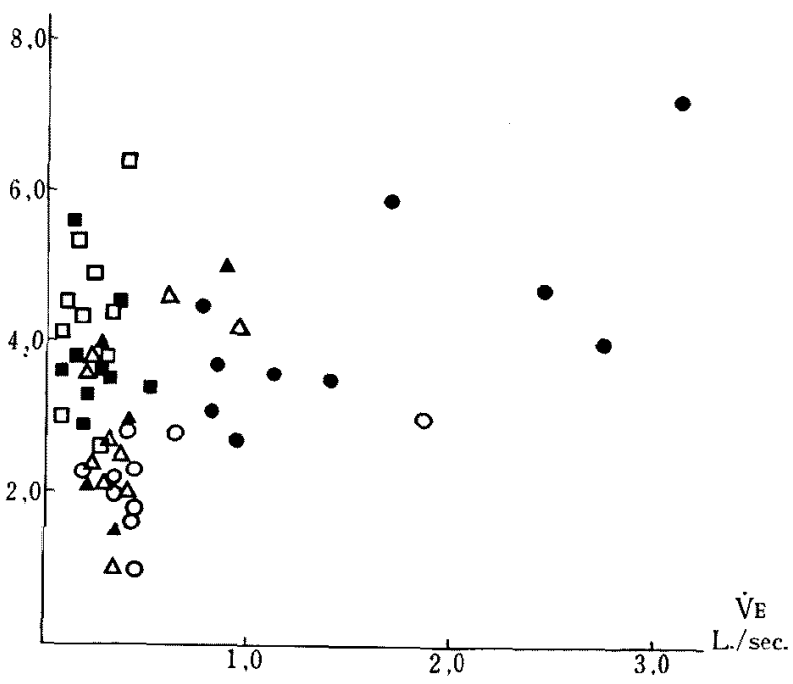

mean rate of air flow

Fig. 13. Mean rate of increase in alveolar $\mathrm{CO}_{2}$ tension plotted against mean rate of air flow in the 2 nd phase.

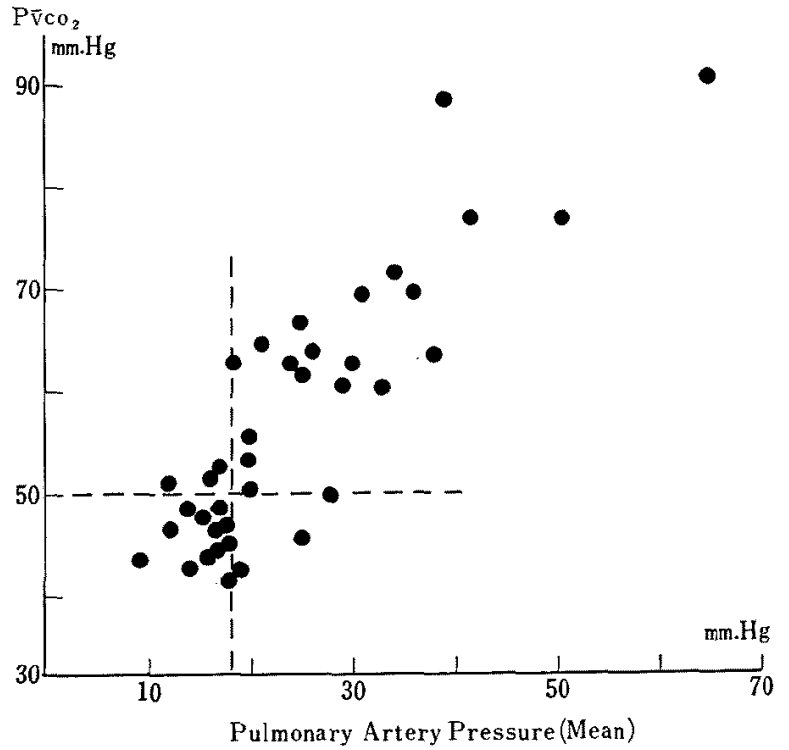

Fig. 14. Correlation between mixed venous $\mathrm{CO}_{2}$ tension and pulmonary artery pressure (Mean) in the patients with pulmonary emphysema. Values shown in this figure are measured by catheterization technics. 
air flow of forced expiration decreases progressively after peak flow, but that a fairly large rate of flow is maintained for the major part (Fig. 7). ${ }^{11}$ In normal subjects the initial alveolar gas of the 2nd phase was always delivered on the ascending stage of the peak flow. On the contrary, in many patients with emphysema, the initial alveolar gas of the 2nd phase was delivered with suggestive POC (Point Of Closure by check valve mechanism) after the peak flow (Fig. 11). This accounts for the results that the mean ratc of air flow in the 2nd phase of maximal expiration remained almost unchanged with hyperventilation in emphysema cases, despite an increasing rate of the peak flow. According to Sivertson and Fowler, ${ }^{4)}$ the patients with emphysema showed an increased mean rate of change in $\mathrm{P}_{\mathrm{ACO}_{2}}$ in the 2nd phase of forced expiration after hyperventilation than that after normal breathing. However, in the present study, no significant change was observed. In emphysema it is well known that an expiratory level is elevated during hyperventilation. Furthermore, airway resistance and pulmonary pressure should be increased within the succeeding forced expiration. This appeared to reduce the pulmonary blood flow and the ratio of pulmonary blood flow per alvcolar lung volume, in a manner similar to that obscrved with the Valsalva maneuver. ${ }^{13)-18}$ ) In this study, knowledge relating to the ratio of rate of pulmonary blood flow per alveolar lung volume throughout the entire respiratory cycle was not available, since events were limited to the expiratory phase of a single respiratory cycle.

On the analysis of an individual case, the value of initial $\mathrm{P}_{\mathrm{ACO} 2}$ in the 2nd phase was slightly lower than the end-tidal $\mathrm{P}_{\mathrm{ACO}_{2}}$; and the average value of expired volumes in the 1 st phase was substracted from the average value of tidal volumes. During natural breathing, normal subjects and patients with emphysema delivered $90 \mathrm{ml}$. and $30 \mathrm{ml}$. of pure alveolar gas respectively in each tidal air. During hyperventilation, the former delivered $1,340 \mathrm{ml}$. of pure alveolar gas and the latter $190 \mathrm{ml}$. (Table I, II). This indicates the limited ability of patients with emphysema to increase an effective alveolar ventilation voluntarily. In the same patients, the large difference between $\mathrm{P}_{\bar{v}^{2} O_{2}}$ and $\mathrm{P}_{\mathrm{ACO}_{2}}$ observed in the 2nd phase indicates that the gas exhaled must have largely come from the alveoli with a high ventilation/ pefusion ratio. The expired alveolar gas may present apparent rates of increase in $\mathrm{P}_{\mathrm{ACO}}$ that to some extent exceed the intrapulmonary rates of increase in $\mathrm{P}_{\mathrm{ACO} 2}$. However, they afford a convenient means of contrasting the normal and emphysematous state. According to Sivertson and Fowler, ${ }^{4}$ the normal or large apparent values of $\dot{Q} / E L V$ indicate that perfusion is not reduced but that ventilation must be increased in the overventilated alveoli. In their description, " increasing the ventilation of overventilated alveoli is relatively less effective in $\mathrm{CO}_{2}$ elimination from the blood than is a proportionate increase in normally ventilated alveoli." These chracteristics of hyperventilated alveoli have been mentioned as 'alveolar dead space.'19)

In patients with emphysema, it is well known that there is a marked 
variation in ventilation/perfusion ratios in different parts of the lung. As DuBois ${ }^{13)}$ has described, the $\mathrm{P}_{\mathrm{ACO} 2}$ have fluctuations according to 'time' or ' phase of the respiratory cycle,' in addition to distribution according to ventilation and blood flow. It has been theorized by Riley ${ }^{20)}$ that the mean arterial $\mathrm{CO}_{2}$ tension should be identical with the mean alveolar $\mathrm{CO}_{2}$ tension. This theoretical mean tension has been designated as 'ideal' tension by Riley. ${ }^{21)} \mathrm{Rahn}^{22}$ has shown that the $\mathrm{P}_{\mathrm{ACO} 2}$ obtained by sampling from the last fraction of each tidal volume is in very close agreement with the arterial $\mathrm{CO}_{2}$ tension in normal subjects. On the other hand, they observed on the average of a 3-4 mm.Hg higher $\mathrm{CO}_{2}$ for the Haldane technique of sampling air than the arterial blood in normal subjects. ${ }^{20122}$ Even at present, a puncture method is commonly used for the analysis of arterial blood. However, this requires an arterial punture and considerable skill in the determination of arterial $\mathrm{CO}_{2}$ tension, since any single determination of arterial $\mathrm{CO}_{2}$ tension by the bubble method can only be read with an accuracy of $\pm 3 \mathrm{~mm} . \mathrm{Hg}$ $\mathrm{CO}_{2}$ tension. ${ }^{23)}$ On the other hand, methods of analyzing alveolar gas continuously offer many practical advantages, with the recent availability of the rapid infrared $\mathrm{CO}_{2}$ analyzer (its accuracy is $\pm 1 \mathrm{~mm} . \mathrm{Hg}$ ). A rapid infrared gas analyzer has been used for the determination of $\mathrm{P}_{\overline{\mathrm{v}}_{2}}$ by a bag rebreathing method. ${ }^{12) 5)}$ According to Collier, ${ }^{1)}$ if gas mixtures carefully adapted to individual requirements are used, the plateau $\mathrm{CO}_{2}$ tension as obtained by rebreathing of a small volume of a $\mathrm{CO}_{2}$ mixture during spontaneous breathing in about 18 seconds may represent $\mathrm{P}_{\overline{\mathrm{v}}_{\mathrm{CO}} 2}$. By this method, $\mathrm{P}_{\overline{\mathrm{v}}_{\mathrm{CO}}}$ can be adequately determined in patients with heart and/or lung disease, with an accuracy of $\pm 3 \mathrm{~mm} . \mathrm{Hg} \mathrm{CO}$ Cension. $^{11} \quad$ Although it is customary to represent the degree of hypercapnia by arterial $\mathrm{CO}_{2}$ tension, the mixed venous blood $\mathrm{CO}_{2}$ is equally representative. The findings shown in Fig. 14 suggest that the degree of pulmonary hypertension varies directly with the severity of hypercapnia, and that hypercapnia as well as anoxia may be important in the genesis of pulmonary hypertension in patients with chronic emphysema. ${ }^{716(24)-26)}$ This is supported by the gencral knowledge that hypercapnia is the consequence of ineffective alveolar ventilation and is always associated with anoxia unless the individual is inhaling oxygen with a partial pressure greater than that in room air. The correlation between $\mathrm{P}_{\overline{\mathrm{v}}} \mathrm{CO}_{2}$ and pulmonary artery pressure will be useful in estimation of the pulmonary hypertension from the value of expired $\mathrm{P}_{\mathrm{ACO}_{2}}$ instead of catheterization procedure in patients with a $\mathrm{P}_{\overline{\mathrm{v}} \mathrm{CO}_{2}}$ of more than $55 \mathrm{~mm} . \mathrm{Hg}$.

Suskind and $\mathrm{Rahn}^{27)}$ pointed out that the $\mathrm{A}-\mathrm{V} \mathrm{CO}_{2}$ difference was reasonably constant in a respiratory steady state despite a wide variation in cardiac output. In view of this finding, Collier and his coworkers ${ }^{2)}$ assumed a constant $\mathrm{A}-\mathrm{V} \mathrm{CO} \mathrm{CO}_{2}$ tension difference of $6 \mathrm{~mm} . \mathrm{Hg}$ in both normal subjects and patients with heart or lung disease. They employed a ' rebreathing method' for determination of $\mathrm{P}_{\overline{\mathrm{V}}_{\mathrm{CO}}}$, and estimated the arterial $\mathrm{CO}_{2}$ tension, substracting a fixed $\mathrm{A}-\mathrm{V} \mathrm{CO} \mathrm{CO}_{2}$ tension difference of $6 \mathrm{~mm} . \mathrm{Hg}$ from the $\mathrm{P}_{\overline{\mathrm{V}} \mathrm{CO}_{2}}$. In our 
17 patients, the arterial blood and expired alvcolar gas were sampled simultaneously. The arterial $\mathrm{CO}_{2}$ tension was compared with the endtidal $\mathbf{P}_{\mathrm{ACO}}$, the $\mathrm{P}_{\mathrm{ACO}_{2}}$ of maximal expiration following natural breathing and the estimated $\mathrm{P}_{\overline{\mathrm{V}} \mathrm{CO}_{2}}$ (the maximal value of forced expiration after breathholding). The end tidal-arterial $\mathrm{CO}_{2}$ tension difference was calculated for patients with emphysema, and an average valuc of $-10 \mathrm{~mm} . \mathrm{Hg}$ was obtained (Table I). ${ }^{28}$ In 15 of 17 patients studied, the $\mathbf{P}_{\mathrm{ACO}_{2}}$ of maximal expiration following natural breathing equaled or exceeded the arterial $\mathrm{CO}_{2}$ tension. On the other hand, the measured arterial $\mathrm{CO}_{2}$ tension never exceeded significantly the estimated $\mathrm{P}_{\overline{\mathrm{V}} \mathrm{CO}_{2}}$ in all cases. Though Defares ${ }^{51}$ recently calculated the cardiac output using the indirect Fick's principle in normal subjects, with the aid of the rebreathing method for the estimation of $\mathrm{P}_{\overline{\mathrm{V}} \mathrm{CO}_{2}}$ and sampling the endtidal air for the substitution of arterial $\mathrm{CO}_{2}$ tension, the precision of the rebreathing method, as well as breathholding method, appeared to be too unsatisfactory for the determination of cardiac output. As mentioned above, the $\mathrm{A}-\mathrm{V} \mathrm{CO} \mathrm{CO}_{2}$ tension difference at rest is about $6 \mathrm{~mm} . \mathrm{Hg}$, and an accuracy of about $0.5 \mathrm{~mm} . \mathrm{Hg}$ would be necessary for the determination of cardiac output. Moreover, the end-tidal $\mathrm{P}_{\mathrm{ACO} 2}$ may be considerably lower than the arterial $\mathrm{CO}_{2}$ tension in patients with pulmonary emphysema, which would make the determination of cardiac output by this method impractical or less accurate.

\section{Summary and Conclusion}

Continuous analysis of expired alveolar $\mathrm{CO}_{2}$ tension, using a rapid infrared meter, was made in 10 normal subjects, and 20 patients with chronic pulmonary diseases. An analytical method similar to that previously described by Sivertson and Fowler was used. Arterial blood was sampled and arterial $\mathrm{CO}_{2}$ tension was measured in 17 patients simultaneously with expired alveolar $\mathrm{CO}_{2}$. Right heart catheterization was carried out in 38 patients with pulmonary emphysema.

(1) In many patients, the resting end-tidal $\mathrm{CO}_{2}$ tension was frequently less than normal. In both normal subjects and patients, the upward slope of alveolar $\mathrm{CO}_{2}$ tension decreased toward the end of forced expiration. However, in patients with emphysema a larger rate of increase in expired alveolar $\mathrm{CO}_{2}$ tension, smaller expired volumes and the prolonged duration of forced expiration were observed. In patients, the apparent values of the difference between mixed venous and alveolar $\mathrm{CO}_{2}$ tension were large and the percentage rates of decrease in the difference were normal. This probably indicates that perfusion is not reduced in the overventilated alveoli of the emphysematous lung. These results well coincided with Fowler's observations.

(2) In cases of pulmonary cmphysema, the mean rates of increase in expired alveolar $\mathrm{CO}_{2}$ tension observed during a forced expiration after hyperventilation, remained similar to those observed during a forced expiration after normal breathing. An expiratory level was elevated in patients with emphysema during 
hyperventilation. Within the succeeding forced expiration, air-way resistance and pulmonary pressure must have been increased, consequently the ratio of pulmonary blood flow per alveolar lung volume should be reduced.

(3) In many patients, the end-tidal $\mathrm{CO}_{2}$ tension was lower than the arterial $\mathrm{CO}_{2}$ tension, but the maximal $\mathrm{CO}_{2}$ tension of the forced expiration following normal breathing equaled or slightly exceeded the arterial $\mathrm{CO}_{2}$ tension. On the other hand, the measured arterial $\mathrm{CO}_{2}$ tension never exceeded the estimated mixed venous $\mathrm{CO}_{2}$ tension significantly.

(4) In pulmonary emphysema, the elevated values of mixed venous $\mathrm{CO}_{2}$ tension well corrclated with the degree of pulmonary hypertension. This correlation is proposed for the use in estimating the pulmonary hypertension from the value of expired alveolar $\mathrm{CO}_{2}$ tension in patients with a mixed venous $\mathrm{ClO}_{2}$ tension of more than $55 \mathrm{~mm} . \mathrm{Hg}$.

(Published in J. Jap. Soc. Int. Med. 48: 447, 1959 in Japanese)

\section{REFERENCES}

1. Collier, G.R. : J. Appl. Physiol. 9 : 25, 1956.

2. Hackney, J.D., Sears, C.H., and Collier, C.R. : J. Appl. Physiol. 12 : 425, 1958.

3. DuBois, A.B., Fowler, R.C., Soffer, A., and Fenn, W.O.: J. Appl. Physiol. 4: $526, \cdot 1952$.

4. Sivertson, S.E., and Fowler, W.S.: J. Lab. \& Clin. Med. 47: 869, 1956.

5. Defares, J.G.: J. Appl. Physiol. 13: 159, 1958.

6. Kelsey, J.E., Ohdham, E.C., and Horvath, S.M.: Arch. Int. Med. 99 : 411 , 1957.

7. Murao, M. : Jap. Circulation J. 19: 414, 1956.

8. Singer, R.B., and Hastings, A.B.: Medicine 27 : 223, 1948.

9. DuBois, A.B., Britt, A.G., and Fenn, W.O. : J. Appl. Physiol, 4: 535, 1952.

10. Dayman, H.: J. Clin. Invest. $30: 1175,1951$.

11. Leuallen, E.C., and Fowler, W.S.: Am. Rev. Tub. \& Pulm. Dis. 72 : 783, 1955.

12. Shiraishi, T.: Tokyo J. Med. Scien. 67 (4A): 709, 1959 (in Japanese).

13. DuBois, A.B.: J. Appl. Physicl. 5: 1, 1952.

14. DuBois, A.B., and Marshall, R. : J. Clin. Invest. 36 : 1566, 1957.

15. Smith, R.B., and Hatch, H.B. Jr. : J. Lab. \& Clin. Med. 53 : 686, 1959.

16. Attinger, E.O., and Segal, M.S.: Am. Rev. Resp. Dis. 80: 53, 1959.

17. Rodbard, S.: Am. J. Med. 15: 356, 1953.

18. Matsumoto, Y.: Tokyo Jikeikai Med. J. 70: 706, 1955 (in Japanese).

19. Severinghaus, J.W., and Stupfel, M. : J. Appl. Physiol. 10 : 335, 1957.

20. Riley, R.L., Lilienthal, J.L. Jr., Proemmel, D.D., and Franke, R.E. : Am. J. Physiol. 147 : 191, 199, 1946.

21. Riley, R.L., and Cournand, A.: J. Appl. Physiol. 1 : 825, 1949.

22. Rahn, H.: Am. J. Physiol. 158 : 21, 1949.

23. Riley, R.L., Proemmel, D.D., and Franke, R.E. : J. Biol. Chem. 161 : 621, 1945.

24. Yu, P.N.G., Lovejoy, F.W. Jr., Joos, H.A., Nye, R.E., and MacCann, W.S. : 
J. Clin. Invest. 32 : 130, 1953.

25. Honma, T.: Respiration \& Girculation 7: 643, 1959 (in Japanese).

26. McMichael, J.: Progr. Cardiovasc. Dis. 1 : 446, 1959.

27. Suskind, M., and Rahn, H.: J. Appl. Physiol. 7 : 59, 1954.

28. Saxton, G.A. Jr., and Rayson, G.E.: Fed. Proc. 14: 130, 1955. 